\title{
Amphetamine use and its associated factors in body builders: a study from Tehran, Iran
}

\author{
Hooman Angoorani ${ }^{1,2}$, Hooman Narenjiha ${ }^{1,3}$, Behnoosh Tayyebi ${ }^{4}$, Akhgar Ghassabian $^{5}$, \\ Gelareh Ahmadi ${ }^{5}$, Shervin Assari ${ }^{5}$
}

\begin{abstract}
${ }^{1}$ Iranian Research Center for Substance Abuse and Dependence (IRCSAD), University of Social Welfare and Rehabilitation Science, Tehran, Iran

2Sports and Exercise Medicine Department, Tehran University of Medical Sciences, Iran ${ }^{3}$ Drug Control Head Quarters (DCHQ), Tehran, Iran

${ }^{4}$ Islamic Azad University, Tehran North Branch, Tehran, Iran

${ }^{5}$ Medicine and Health Promotion Institute (MHPI), Tehran, Iran
\end{abstract}

Submitted: 19 February 2009

Accepted: 14 October 2009

Arch Med Sci 2012; 8, 2: 362-367

DOI: 10.5114 /aoms.2012.28566

Copyright (c) 2012 Termedia \& Banach

\section{Abstract}

Introduction: Epidemiological studies on all types of illicit drug use among athletes are essential for both the sport community and drug control achievements. Here, we investigated the prevalence and associated factors of amphetamine use in body builders in Tehran, Iran, 2007.

Material and methods: This study is a secondary analysis of a substance use survey done in 103 randomly selected gymnasia in Tehran (capital city of Iran). The survey was conducted from November 2007 to January 2008 and included 843 randomly selected bodybuilders (aged 40 years or less). By interviews via questionnaires the following data were obtained: age, job, marital status, education level, housing status, average monthly family income, number of family members, gymnasium area $\left(\mathrm{m}^{2}\right)$, number of trainers, number of gymnasium members, initiation time (months), weekly duration of the sporting activity (h), monthly cost of the sporting activity, purpose of participating in sporting activity, and history of anabolic steroid and amphetamine use.

Results: One hundred twenty (13.3\%) body builders reported a history of amphetamine use. According to the results of regression analysis, being married (risk ratio $-R R=0.540$ ), and participating in body building to enhance self-esteem $(R R=0.423)$ or to enhance sport performance $(R R=0.545)$ had protective effects on amphetamine use. However, having university qualifications $(R R=1.843)$, using anabolic steroids $(R R=1.803)$ and participating in sport to maintain fitness $(R R=2.472)$ were linked to increased risk of amphetamine use.

Conclusions: Well-educated bodybuilders were more likely to use amphetamines, and why this is so needs to be discovered. If further studies show that they are not aware of the dangers associated with amphetamine use, providing them with information should be considered.

Key words: amphetamines, athletes, sports, bodybuilders.

\section{Introduction}

The sport-drug relationship has always fascinated the scientific community, and there has been a plethora of research into the patterns of drug abuse in athletes [1]. Participating in sports is believed to be protective against drug abuse [2, 3]. Nevertheless, the prevalence of drug abuse among
Corresponding author: Dr. Hooman Angoorani Research Center for Substance Abuse and Dependence (Darius Institute) Welfare and Rehabilitation University Koodak-yar Ave Daneshjoo Blvd., Evin Tehran, Iran Phone: +98 2122423920 Fax: +98 2122423921 E-mail: h-angoorani@tums.ac.ir 
athletes of different disciplines has prompted many researchers over the years to probe into the whys and the wherefores of this phenomenon $[4,5]$. There seems to be a general consensus among the researchers that in the sport-drug relationship, the kind of drug and different characteristics of a sporting activity are the key factors $[1,6,7]$.

There is a new trend of psychoactive drug use by athletes [8]. Even with strict regulations of doping [9] illicit drugs are used by athletes to help them to enhance performance $[10,11]$. According to one epidemiological investigation, the likelihood of amphetamine use might be higher among people who are engaged in any type of sporting activities, either the competitive or non-competitive forms [12]. Amphetamines do not lessen fatigue but can mask it, and that is what renders them pernicious to the health of athletes $[5,10]$. Those involved in sports that require intense anaerobic activities are more likely to gravitate toward amphetamines because they are believed to prolong anaerobic metabolism [13].

There is little information about amphetamine use in the general population in Iran [14]. The main reason is that it is a relatively new phenomenon in this country [15]. Most studies in the field of drug abuse are focused on opiates, including opium, opium derivates such as juice and residue, and heroin [16-18], and some studies do not even report amphetamine abuse [19]. In 2007, amphetamines were the dominant drugs in $4 \%$ of Iranian drug users [20]. However, considering the huge number of drug dependents in Iran (1.2-1.8 million) [21, 22], the total number would be considerable and is estimated to be between 48,000 and 72,000 . One survey in 15-25 year old participants in Tehran reported the prevalence of $18.5 \%$ for ecstasy abuse, with a higher prevalence in males, lower education level, higher family income and users of other drugs at the same time [23]. There are published reports on amphetamines in different Iranian sub-populations [24]. The highest reported prevalence is $18 \%$ for methamphetamine use among people with high-risk sexual behavior [23].

Here, we investigated the prevalence and associated factors of amphetamine use among a random sample of body builders in Tehran, Iran, in 2007.

\section{Material and methods}

\section{Design and setting}

This is a secondary analysis of a substance abuse survey carried out from November 2007 to January 2008, in Tehran, Iran. The study was funded by the Research Center for Substance Abuse and Dependence and done under the financial support of the Iranian National Drug Control Headquarters.

\section{Samples and sampling}

One hundred and three gymnasia were selected using simple (one level) random sampling (computer-generated random numbers). From these clubs, we invited all $(n=930)$ bodybuilders who were present at the club at the time of sampling. Inclusion criteria were male gender and age of 16 to 40 years. From all who were invited, 843 agreed to participate in our study (response rate $=90.6 \%$ ).

\section{Codes of ethics}

Verbal consent was obtained from the athletes and they were reassured that the data would be kept strictly confidential. All participants were given information about the purpose of the study. Participants' names were not recorded to assure confidentiality (anonymous study). We have conducted this study according to the 'Ethical Principles for Medical Research involving Human Subjects' of the Helsinki Declaration and it is approved by the ethics committee of the Research Center for Substance Abuse and Dependence and the Ministry of Health of the Islamic Republic of Iran.

\section{Process}

Data on participants' social and demographic characteristics, sporting activity patterns and substance abuse history were collected via an interview which took about 45 min for each participant, using structured questionnaires.

\section{Independent variables}

Independent variables included the following variables: age, job, marital status, education level, housing status, average monthly family income, number of family members, gymnasium area $\left(\mathrm{m}^{2}\right)$, number of trainers, number of gymnasium members, initiation time (months), weekly duration of the sporting activity (h), monthly cost of the sporting activity, purpose of participating in the sporting activity, and history of anabolic steroid use. The purpose of participating in the sporting activity was defined by the answer to the following six phrases (yes/no): 1) to gain a higher social level, 2) to attract further attention, 3) to enhance one's self-esteem, 4) to enhance one's sports performance, 5) to have a healthy life, and 6) to maintain one's fitness.

\section{Main outcome}

The dependent variable was amphetamine use (self-reported data). It was assessed by using the following question: "Until now, have you ever tried any type of amphetamines such as crystal meth, glass, MDMA, lover's speed, the love drug, ecstasy, crystal, speed, XTC, E, or X?" Similar items had been 
used by previous researchers on lifetime drug use of adolescents in Iran.

\section{Statistical analysis}

For this survey, a sample size of 900 was determined considering a confidence interval of $2 \%$, for an estimated prevalence of $18 \%$ for methamphetamine use (according to the only existing epidemiological report in Iran [23] and a total number of 7,000 , based on the estimate of the Iran Power Lifting Federation).

The data were analyzed using the SPSS statistical package program. To compare non-normally distributed variables, the Mann-Whitney $U$ test was used and the information is given as median and inter-quartile range (IQR). All independent variables were entered into a multiple logistic regression model to determine the associated factors of amphetamine use in body builders (forward selection method) and the results are reported as relative risks (RR) and 95\% confidence intervals $(95 \% \mathrm{Cl})$. The missing values in the analysis were relatively few. A $p$ value less than 0.05 was considered significant.

\section{Results}

\section{Participants}

From a total of 843 participants with mean age of 25.2 (standard deviation - SD = 5.9) years (minimum of 16 and maximum of 40), 112 (13.3\%) body builders reported a history of amphetamine use (in the form of methamphetamine hydrochloride (meth) or 3,4-methylenedioxy- $\mathrm{N}$-methylamphetamine (MDMA)). We had 106 MDMA users, one meth user, and 6 users of both. Up to the commencement time of the study, the participants had worked out an average of 20 months $(I Q R=42)$ at an average of $6 \mathrm{~h}(\mathrm{IQR}=3)$ per week in gymnasia. They had on average monthly family income of $\$ 631.5(I Q R=\$ 631.5)$ and the sport clubs had on average 2 trainers $(I Q R=1)$ and 160 members $(\mathrm{IQR}=80)$.

\section{Amphetamine users versus non-users}

The amphetamine users and non-users were not significantly different in age, job, monthly family income, marital status, or housing status. However, the proportion of the users who had university qualifications was higher than non-users ( $42.7 \%$ vs. $27.7 \%, p=0.001$ ). Additionally, the rate of concurrent use of anabolic steroids was not significantly different in amphetamine users and non-users (19.6\% vs. $17.1 \% ; p=0.509)$ (Table I).

The different characteristics of the gymnasia (i.e. area and number of trainers and members) and the sporting activity patterns (i.e. initiation time and weekly activity duration) were not significantly different between the two groups. Regarding the purpose of body building, the users reported the pursuit of fitness $(46.4 \%$ vs. $23.4 \%, p<0.001)$ or a healthy life $(64.3 \%$ vs. $44.7 \%, p<0.001)$ more than did the non-users, while the latter cited enhancing self-esteem more than the former $(p<0.001)$ (Table I).

\section{Associated factors of amphetamine use in body builders}

The results of our regression analysis demonstrated that being married $(R R=0.540,95 \% \mathrm{Cl}=$ 0.312-0.935, $p=0.028$ ), participating in sporting activity to enhance self-esteem $(R R=0.423$, $95 \% \mathrm{Cl}=0.268-0.665, p<0.001)$ or to enhance sports performance $(\mathrm{RR}=0.545,95 \% \mathrm{Cl}=0.303$ $0.980, p=0.043$ ) were protective factors in body builders for abusing amphetamines. On the other hand, having university qualifications ( $R R=1.843$, $95 \% \mathrm{Cl}=1.182-2.873, p=0.007)$, using anabolic steroids $(\mathrm{RR}=1.803,95 \% \mathrm{Cl}=1.029-3.160, p=0.039)$ and participating in sporting activity to maintain fitness ( $\mathrm{RR}=2.472,95 \% \mathrm{Cl}=1.587-3.851, p<0.001)$ were strong risk factors for abuse of amphetamines in body builders.

\section{Discussion}

According to this study, one in eight body builders in Tehran reported amphetamine use. Among the body builders, being married and participating in body building to enhance self-esteem or to enhance sport performance were associated with a lower likelihood of amphetamine use. However, having university qualifications, using anabolic steroids and participating in sporting activity to maintain fitness were associated with a higher likelihood of amphetamine use in body builders.

In the present study, $13 \%$ of the body builders admitted to amphetamine use (mostly ecstasy). A previous study in Iran indicated a rise in amphetamine use (especially ecstasy) among the young generation [25], the same as a United Nations' report [26] and other regional investigations [27, 28]. Despite worldwide concern, it is impossible to estimate accurately the actual prevalence of amphetamine use in the general population, because this substance is used mostly by the young population in recreational places and ceremonies [29] and only a few users are likely to refer for treatment or to judiciary centers [30]. In addition, strict anti-doping regulations and screenings [9] lead to relative success in discouraging athletes from amphetamine use in competitions. Therefore, studies in this group at competitive levels are liable to underestimate the facts about the use of this particular substance by sportspersons. 
Table I. Socio-demographic characteristics and sporting activity patterns in body builders with and without history of amphetamine use

\begin{tabular}{|c|c|c|c|}
\hline \multirow[t]{2}{*}{ Parameter } & \multicolumn{2}{|c|}{ History of amphetamine use } & \multirow[t]{2}{*}{ Value of $p^{a}$} \\
\hline & $\begin{array}{c}\text { Yes, } N=112 \\
\text { Median (IQR) }\end{array}$ & $\begin{array}{c}\text { No, } N=731 \\
\text { Median (IQR) }\end{array}$ & \\
\hline Age [years] & $23(7)$ & $24(9)$ & 0.544 \\
\hline Number of family members & $4(2)$ & $4(2)$ & 0.223 \\
\hline Monthly family income [\$] & $736.8(842.2)$ & $631.5(631.5)$ & 0.073 \\
\hline Gymnasium area $\left[\mathrm{m}^{2}\right]$ & $250(200)$ & $250(140)$ & 0.983 \\
\hline Number of trainers & $2(1)$ & $2(1)$ & 0.407 \\
\hline Number of members & $150(100)$ & $160(80)$ & 0.084 \\
\hline Monthly membership cost [\$] & $13.2(13.0)$ & $12.6(9.5)$ & 0.715 \\
\hline Initiation time of sport [months] & $24(42)$ & $20.5(42)$ & 0.833 \\
\hline \multirow[t]{2}{*}{ Weekly duration of sport [h] } & $6(4)$ & $6(4)$ & 0.162 \\
\hline & $N(\%)$ & $N(\%)$ & Value of $p^{b}$ \\
\hline Being married & $21(18.8)$ & $196(26.9)$ & 0.067 \\
\hline University qualifications & $47(42.7)$ & $198(27.7)$ & $0.001^{*}$ \\
\hline Self-owned home & $34(30.4)$ & $241(33.3)$ & 0.539 \\
\hline Being jobless & $30(26.8)$ & $196(26.8)$ & 0.995 \\
\hline Using steroids & $22(19.6)$ & $125(17.1)$ & 0.509 \\
\hline \multicolumn{4}{|l|}{ Doing sport to: } \\
\hline Gain a higher social level & $15(13.4)$ & $207(28.4)$ & $0.001^{*}$ \\
\hline Attract further attention & $13(11.6)$ & $117(16.0)$ & 0.228 \\
\hline Enhance one's self-esteem & $42(37.5)$ & $402(55.1)$ & $0.001^{*}$ \\
\hline Enhance one's sports performance & $18(16.1)$ & $176(24.1)$ & 0.060 \\
\hline Have a healthy life & $72(64.3)$ & $326(44.7)$ & $<0.001^{*}$ \\
\hline Maintain one's fitness & $52(46.4)$ & $171(23.4)$ & $<0.001^{\star}$ \\
\hline
\end{tabular}

${ }^{*}$ value of $p$ less than 0.05 , a Mann-Whitney $U$ test, ${ }^{b} \chi^{2}$ test

The higher likelihood of amphetamine use among those with a higher educational degree may be related to the lack of knowledge about the dangers of amphetamines in well-educated bodybuilders. The literature also shows a high rate of drug use among highly educated people [31]. In Iran, a link between poor knowledge about amphetamines and ecstasy has been reported previously [23, 32, 33]. Therefore, providing accurate information may be critically important to prevent amphetamine abuse. According to the literature, informing about the hazards of drug use may decrease drug use prevalence in communities [34].

In the present study, employment was not related to amphetamine use, but being married and having university qualifications were associated with amphetamine use: the body builders who were married used amphetamines less, while those who had university qualifications had a higher likelihood of amphetamine use. A literature review shows some evidence for no link between socio-demographic characteristics and amphetamine use [35] and no association between lower levels of education and amphetamine use [30, 32]. Some studies also show that individuals in stable relationships may be at lower risk for illicit drug use [32]. The higher rate of drug use among people with higher educational level may be explained by the gap between knowledge and behavior and the link between impulsivity and illicit drug use [36]. It has been shown that a proportion of people use illicit drugs despite being aware of its consequences [37].

Similar to current findings, a link between the history of anabolic steroid use and the likelihood of psychotropic drug abuse has been reported [38-40]. Both amphetamines [32] and anabolic steroids tend to be used concurrently with other substances [38]. This link may be explained by similar biological mechanisms of substance use and dependency [39]. This finding highlights the need for controlling for another when one is reported.

As athletes use amphetamines not only for recreation, but also for performance improvement $[11,13]$, we expect a link between amphetamine use 
and sport variables. Within sport related characteristics in the present study, the only variable with such a link was the motivation for body building. Participation in body building to maintain fitness was linked to higher likelihood of amphetamine use, as opposed to those who sought better selfesteem and sports performance. The literature indicates a higher likelihood of illicit drug use among athletes who participate in sports at competitive levels $[1,4]$.

Body builders may use amphetamines for recreation or for enhancement of sport performance, but the present study did not assess these possible motivations for amphetamine use. We also did not ask about the level of knowledge about amphetamines. This information could shed light on the possible preventive strategies to explain if drug educational programs can be helpful in this population; but further studies are needed in this regard.

It is widely acknowledged that illicit drug use is a difficult subject to study. We, too, encountered a number of hurdles that limited the scope of the present study. For instance, a considerable amount of missing data on the details of the body builders' amphetamine use precluded us from analyzing their drug use patterns. The data were all self-reported, and the cross-sectional design of the study rendered us unable to define a causative relationship between amphetamine use and the associated factors. However, as the athletes in the present study were interviewed about amphetamine use in a setting outside competitions and there was no fear of doping regulations, the results of this study should be relatively close to reality. We should add to the above that body building is not an Olympic sport and usually there is no doping control.

In this study we used interviews for data collection. The literature shows that self-reported illicit drug use can be both reliable and valid in different populations [41]. However, for further studies, we suggest using self-administered questionnaires for drug use surveys because they have been shown to increase the rate of drug use as opposed to interviews [42].

In conclusion, the possible causes of the higher likelihood of amphetamine use among bodybuilders with higher education warrants further studies. If further studies confirm a lack of knowledge of hazards associated with amphetamine use, providing appropriate information should be considered. We hope that the results of the present study can serve as a baseline for future studies on amphetamine abuse and its associated risk factors in athletes.

\section{Acknowledgments}

This research was carried out under the financial and scientific supervision of the Research Cen- ter for Substance Abuse and Dependency (Darius Institute).

\section{References}

1. Peretti-Watel P, Guagliardo V, Verger P, Pruvost J, Mignon $\mathrm{P}$, Obadia Y. Sporting activity and drug use: Alcohol, cigarette and cannabis use among elite student athletes. Addiction 2003; 98: 1249-56.

2. McArdle P, Wiegersma A, Gilvarry E, et al. International variations in youth drug use: the effect of individual behaviors, peer and family influences, and geographical location. Eur Addict Res 2000; 6: 163-9.

3. Pate RR, Trost SG, Levin S, Dowda M. Sports participation and health-related behaviors among US youth. Arch Pediatr Adolesc Med 2000; 154: 904-11.

4. Lorene FO, Peretti-Watel P, Grelot L. Cannabis use to enhance sportive and non-sportive performances among French sport students. Addict Behave 2005; 30: 1382-91.

5. Wagner JC. Abuse of drugs used to enhance athletic performance. Am J Hosp Pharm 1989; 46: 2059-67.

6. Challier B, Chau N, Predine R, Choquet M, Legras B. Associations of family environment and individual factors with tobacco, alcohol and illicit drug use in adolescents. Eur J Epidemiol 2000; 16: 33-42.

7. Margaria R, Aghemo P, Rovelli E. The effect of some drugs on the maximal capacity of athletic performance in man. Eur J Appl Physiol 1964; 20: 281-7.

8. The world anti doping code: The 2008 prohibited list, international standard. The world anti doping agent. Available at: http://www.wada-ama.org/rtecontent/ document/2008_List_En.pdf. Accessed 2 May 2008.

9. Clarkson PM, Thompson HS. Drugs and sport. Research findings and limitations. Sports Med 1997; 24: 366-84.

10. Laties VG, Weiss B. The amphetamine margin in sports. Fed Proc 1981; 40: 2689-92.

11. Toohey JV. Non-medical drug use among intercollegiate athletes at five American universities. Bulletin on Narcotics UNODC 1978; $3: 7$.

12. Alan JG. Central nervous system stimulants. Best Pract Res Clin Endocrinol Metab 2000; 14: 79-88.

13. Feizzadeh A. Ecstasy: a new substance. Social Welfare 2002; 1: 105-16.

14. Mokri A. Brief overview of the status of drug abuse in Iran. 2002. Available at: www.ams.ac.ir/AIM/0253/0253184.htm

15. Alizadeh N, Mohammadi A, Tabrizchi M. Rapid screening of methamphetamines in human serum by headspace solid-phase microextraction using a dodecylsulfate-doped polypyrrole film coupled to ion mobility spectrometry. J Chromatogr A 2008; 1183: 21-8.

16. UNODC. Epidemiology of drug use in Iran. 2009. Available athttp://www.unodc.org/iran/en/epidemiology.html. Accessed 2 May 2008.

17. Shadnia S, Esmaily H, Sasanian G, Pajoumand A, Hassanian-Moghaddam H, Abdollahi M. Pattern of acute poisoning in Tehran-Iran in 2003. Hum Exp Toxicol 2007; 26: 753-6.

18. Moghadamnia AA, Abdollahi M. An epidemiological study of acute poisonings in northern Islamic Republic of Iran. East Medit Health J 2002; 8: 88-94.

19. Daneshmandan N, Narenjiha H, Tehrani K, Assari S, Khoddami-Vishteh HR. Initiation to the first drug use among substance dependent persons in Iran. Substance Use Misuse 2011: 46: 1124-41.

20. Yassami MT, Shahmohammadi D, et al. Epidemiology of drug abuse. In I.R. Iran; Ministry of Health and Medical 
Education; Drug Control Headquarters 2002 (not published, In Persian).

21. Narenjiha H, Rafiey H, Baghestani AH, et al. Rapid situation assessment of drug abuse and drug dependence in Iran. DARIUS Institute 2005 (In Farsi, not published).

22. Barooni S, Mehrdad R, Akbari E. A survey of Ecstasy use among 15-25 year-olds in five areas of Tehran. Tehran University Medical Journal (TUMJ) 2007; 65: 49-54.

23. Hajiabdolbaghi M, Razani N, Karami N, et al. Insights from a survey of sexual behavior among a group of at-risk women in Tehran, Iran, 2006. AIDS Educ Prev 2007; 19: 519-30.

24. United Nations Office in Drug and Crime. 2006 World Drug Report. Geneva: United Nations 2006.

25. Iversen L. Speed, ecstasy, ritalin: the science of amphetamines. Addiction 2007; 102: 1005-7.

26. Rawson RA, Gonzales R, McCann M, Ling W. Use of methamphetamine by young people: is there reason for concern? Addiction 2007; 102: 1021-2.

27. Hao W, Xiao S, Liu T, et al. The second National Epidemiological Survey on illicit drug use at six highprevalence areas in China: prevalence rates and use patterns. Addiction 2002; 97: 1305-15.

28. Degenhardt L, Coffey C, Moran P, Carlin JB, Patton GC. The predictors and consequences of adolescent amphetamine use: findings from the Victoria Adolescent Health Cohort Study. Addiction 2007; 102: 1076-84.

29. Williams P. Correlates of Ecstasy use in middle age and beyond. Drug Alcohol Rev 2005; 24: 33-8.

30. Matano RA, Wanat SF, Westrup D, Koopman C, Whitsell SD. Prevalence of alcohol and drug use in a highly educated workforce. J Behav Health Serv Res 2002; 29: 30-44.

31. Hasanian Moghadam H, Farnaghi F, Sarjami S, Zirakzadeh $\mathrm{H}$. The extent of awareness among medical students of Shahid Beheshti University of Medical Sciences in the case of ecstasy. Sci J Forensic Med 2005; 11: 128-31.

32. Deas-Nesmith D, Brady KT, Withe R, Campbell S. HIV-Risk behaviors in adolescence substance abusers. J Subst Abuse Treat 1999; 16: 169-72.

33. Cuijpers P. Effective ingredients of school-based drug prevention programs. A systematic review. Addict Behav 2002; 27: 1009-23.

34. Degenhardt L, Coffey C, Carlin JB, Moran P, Patton GC. Who are the new amphetamine users? A 10-year prospective study of young Australians. Addiction 2007; 102: 1269-79.

35. Yang MS, Ko YC, Wen JK. Prevalence and related factors of substances use in female aborigines in southern Taiwan. Kaohsiung J Med Sci 1996; 12: 634-40.

36. Cottler LB, Womack SB, Compton WM, Ben-Abdallah A. Ecstasy abuse and dependence among adolescents and young adults: applicability and reliability of DSM-IV criteria. Hum Psychopharmacol 2001; 16: 599-606.

37. Kindlundh AM, Hagekull B, Isacson DG. Adolescent use of anabolic-androgenic steroids and relations to selfreports of social, personality and health aspects. Eur J Public Health 2001; 11: 322-8.

38. Lukas SE. CNS effects and abuse liability of anabolicandrogenic steroids. Ann Rev Pharmacol Toxicol 1996; 36: 333-57.

39. Bauman A, Phongsavan P. Epidemiology of substance use in adolescence: prevalence, trends and policy implications. Drug Alcohol Depend 1999; 55: 187-207.

40. Darke S. Self-report among injecting drug users: a review. Drug Alcohol Depend 1998; 51: 253-63.
41. Harrison L. The validity of self-reported drug use in survey research: an overview and critique of research methods. NIDA Res Monogr 1997; 167: 17-36.

42. Abnet CC, Saadatian-Elahi M, Pourshams A, et al. Reliability and validity of opiate use self-report in a population at high risk for esophageal cancer in Golestan, Iran. Cancer Epidemiol Biomarkers Prev 2004; 13: 1068-70. 